\title{
Present and prospective role of the oceans and ice cover in the world climate
}

\author{
Peter Wadhams , $^{\text {** }}$ \\ ${ }^{1}$ Department of Applied Mathematics and Theoretical Physics, University of Cambridge, UK
}

\begin{abstract}
In this article I will focus on the role of the ice-covered oceans, particularly the Arctic, because global warming affects the Arctic more than any other part of the world, and the decline in ice extent which this induces has serious feedback effects upon the entire global climate, including that of the non-polar oceans.
\end{abstract}

\section{Observed change and causes}

Huge changes have occurred to the ice of the Arctic and Antarctic Oceans since I started to study ice properties in 1970. The ice in the Arctic has shrunk in area and thinned by $50 \%$ so that today the summer ice cover has only a quarter of the volume of the ice in the 1970s. Soon it will be gone. Winter ice cover is also in retreat, and although it will last longer, its survival time is now being considered in decades rather than millennia. The ice type has changed as well; in 1970 most of the Arctic ice cover was composed of multi-year ice, which circulates within the Arctic Basin for many years, growing steadily thicker and more deformed, with deep pressure ridges extending to $50 \mathrm{~m}$ depth or more.

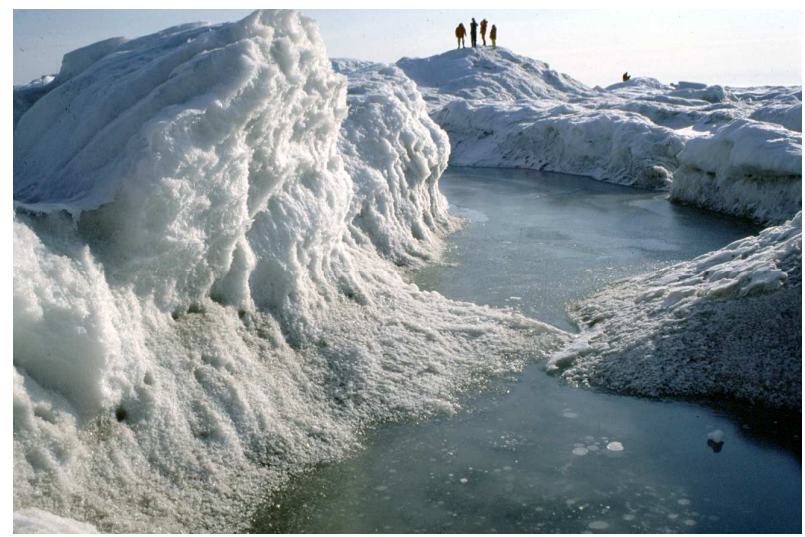

Fig. 1. Thick multi-year ice in the Beaufort Sea, summer of 1970s, showing high rugged topography, deep melt pools and many ridges.

Today most of the ice is first-year ice, which grows and melts within a single year, has little ridging, and extends to a depth of only $1.5 \mathrm{~m}$ or so [1].

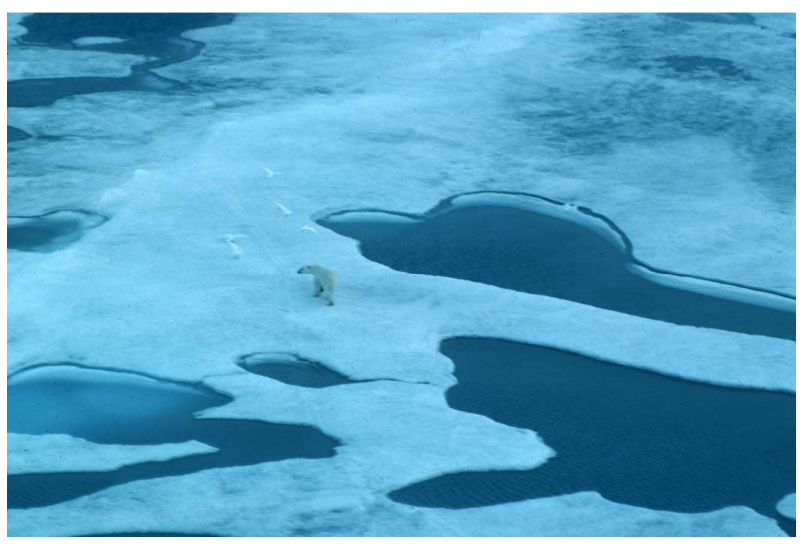

Fig. 2. First-year ice in Arctic Basin today, showing 1 - $1.5 \mathrm{~m}$ ice with level surface and few ridges.

The change of ice type can be ascribed to a change of the wind system prevailing in the Arctic and thus a change in the pattern of ice motion. But more important than this is the fact that the ice is growing much more slowly as a consequence of global warming. Adding carbon dioxide to the atmosphere causes a temperature rise. There is no way out of this conclusion; it is basic physics due to the imbalance between the fixed radiation input from the sun and a reduced output of long-wave radiation from the surface of planet Earth due to absorption of part of the outgoing energy by gases in the atmosphere, notably carbon dioxide and methane. A balance can only be maintained by a temperature rise of the planet. To deny this, as figures like the current US president do, is akin to denying gravity or asserting that the Earth is flat.

But an additional factor is at work in the Arctic, the so-called Arctic Amplification Effect. It is found that the Arctic is warming at 2-4 times (today 2.8 times) the mean warming rate of the rest of the planet. Thus the temperature of the Earth as a whole has increased by about $0.9^{\circ} \mathrm{C}$ since pre-industrial times while the Arctic has warmed by $2.5-3^{\circ} \mathrm{C}$. Many reasons have been 
adduced for this, of which the most likely is that the extra heat absorbed in the Arctic is distributed through a thinner layer of troposphere than in lower latitudes, thus causing a greater temperature rise. Once this effect takes hold, it is exacerbated by the fact that the retreat of sea ice causes an albedo feedback from the replacement of a snow or ice surface with an albedo of 0.8 (for fresh snow) by a water surface with an albedo of less than 0.1 . But it must be emphasized that historic temperature data show that Arctic amplification preceded albedo feedback due to ice retreat, though ice changes have made the factor of amplification greater.

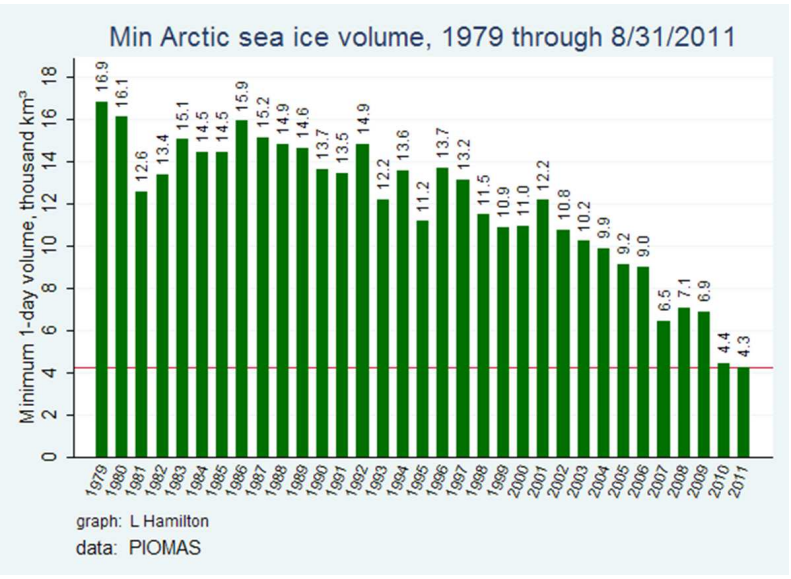

Fig. 3. Minimum Arctic sea ice volume (September) from 1979 to 2011 , showing loss of three-quarters of 1979 volume.

\section{Consequences}

The global consequences of this change are very serious, and are already showing themselves. They operate through a series of positive feedback mechanisms, which enhance the rate of warming. Overall, they demonstrate that Arctic warming is a driver for global change and is not just a consequence. The feedbacks include:

1. An albedo feedback. Albedo is the fraction of incoming solar radiation which is immediately reflected back out into space. For fresh snow on ice it is $80-90 \%$, for melting ice in summer $40-60 \%$, and for open water or tundra it is less than $10 \%$. As sea ice retreats the amount of solar radiation retained by the Earth's surface increases. This applies both to sea ice and to snow, which is also in retreat, since regions previously thought of as characteristically snow-covered, such as Alaska, northern Siberia and the Canadian Arctic islands, are now snow-free by early summer. We have recently shown that snow and ice albedo change together cause an increase of $40 \%$ in the energy absorbed by the Earth in relation to the effect of $\mathrm{CO} 2$ alone, a massive change [2].

2. Accelerated melt from Greenland. Before the 1980s little or no melt occurred on the Greenland ice sheet, which has an elevation of 2-3 km and is therefore very cold throughout the year. Then melt began around the edges of the ice sheet, at low altitude. Now it occurs all over the ice sheet surface in summer, amounting to $300 \mathrm{cu} \mathrm{km}$ per year. The melt water works its way down through the ice sheet through fissures and large melt holes known as moulins, which transport latent heat into the interior and base of the ice sheet, enhancing glacier flow and iceberg discharge, The result is that Greenland is now a bigger source of global sea level rise than the melt from all other glaciers combined, plus rise due to warming of the oceans. Melt from the Antarctic ice sheet is beginning too, and potentially can become greater than melt from Greenland because of the greater surface area. This has caused a radical updating of estimates of sea level rise by the year 2100, which was estimated as 30$60 \mathrm{~cm}$ in the Fourth IPCC assessment and up to $90 \mathrm{~cm}$ in the Fifth (2013). Today, new discoveries and observations of ice sheet processes have led to a range of estimates which allow a possibility, albeit small, of a rise of $2 \mathrm{~m}$ by 2100 [3]. This would be catastrophic for coastal cities worldwide, including Venice in Italy, and also for densely populated coastal lowlands such as Bangladesh, where flood defences cannot be afforded and destructive storm surges are increasingly likely.

3. A potentially serious methane threat. The wide continental shelves which occupy one third of the Arctic Ocean, mainly the seas north of Siberia, have depths of only 50-100 m and are now ice-free in summer. Solar radiation heats up the water to several degrees (more than $5^{\circ} \mathrm{C}$, and $\mathrm{I}$ have measured $11^{\circ} \mathrm{C}$ in 2014). This thaws a protective layer of permafrost on the seabed which has existed since the last Ice Age; such a thaw never occurred when the region was ice-covered even in summer (up until 2005) ensuring sea water temperatures below $0^{\circ} \mathrm{C}$. The present melt of seabed permafrost permits a pressure release which allows methane hydrates in the underlying sediments to disintegrate into methane gas which forces its way up via fissures known as taliks into the water column and hence to the atmosphere. The fear is that the whole protective layer will be lost, allowing a huge pulse of methane to emerge in a short time. If just $8 \%$ of the methane in the sediments comes out quickly, we have calculated that this will cause an immediate warming of $0.6^{\circ} \mathrm{C}$ worldwide, which would be catastrophic [4].

4. An increase in extreme weather events. These have been occurring with increasing frequency since 2005 (the first year of extensive sea ice shrinkage in summer) and consist of periods of extreme heat or cold in mid-northern latitudes. A famous event in Europe was the "Beast from the East" period of extreme cold in early 2018. The cause appears to be meandering of the jetstream, formerly a sharp wind boundary between polar and tropical air, which is now reduced in strength because of warming of the polar air mass which lowers the temperature difference between the two air systems [5]. The meanders created by wind slowing allow cold air to get further south and hot air to get further north at different longitudes. The extreme temporal variability is a threat to crop production, which is most intensive in temperate northern latitudes, and the impact is likely to get worse at a time when world population continues to increase rapidly.

5. There is a decrease in the strength of the Atlantic thermohaline circulation, leading to cooler water off NW Europe and warmer water in the Gulf of Mexico. 
This occurs because the circulation, a worldwide phenomenon driven by temperature and salinity differences over the ocean, requires narrow sinking regions for continuity (justifying its title of the "Global conveyor belt"). An important sinking region in the far northern Atlantic used to be a small area around $75^{\circ} \mathrm{N}$, $0^{\circ} \mathrm{W}$, beneath a feature known as the Odden ice tongue, where southward flowing ice from the Arctic was diverted out into the Greenland Sea by an offshore ridge. Within this region new ice used to grow in winter in the form of pancake ice, which grows very fast because wind and waves prevent the formation of continuous sheets so that heat flow from ocean to atmosphere continues undiminished. The rapid ice formation caused rejection of brine from the new ice, increasing the density of the surface water and allowing it to sink to deep levels $(2500 \mathrm{~m}$ or more) in the form of rotating circular cylinders called "chimneys", which we have studied intensively [6]. Today climate warming has caused ice production to cease in the Odden, so this form of convection has stopped. Models predict a weakening of the whole Atlantic themohaline circulation which will mean that less warm water is transported north to the seas off NW Europe, while the increased pool of warm surface water left in the tropical Atlantic will lead to greater intensity of hurricanes in the Caribbean and southern US.

\section{Actions that are needed}

What can we do about all this? The results show that all man-induced climate change effects are interconnected; we cannot isolate one phenomenon such as sea ice retreat. A recent report which shows that one million species are in danger of extinction also demonstrates how we have destroyed our planet's life support system by mindless development and misuse of technology. The accelerated changes in global climate which can be traced back to a particular originating change - sea ice retreat - are aspects of an overall global warming which is accelerating. And there is no let-up to the rate at which we are insulting the planet; despite endless reports from IPCC and the Paris climate agreement of 2015 there is no reduction at all in the rate of exponential rise of the $\mathrm{CO} 2$ level in the atmosphere, as demonstrated by the observatory on Mauna Loa in Hawaii which has kept records since 1958. The curve began at $320 \mathrm{ppm}$ (immediate postglacial level was 280), a modest rise over natural levels, but by this year (May) it had reached 415 and is accelerating in its rate of rise. Global temperature rise is closely tied to carbon dioxide rise (with methane now adding about a quarter to the warming), so the present increase is a recipe for disaster.

The reality is that despite the promises made by national governments at the time of signing of the Paris agreement, the growth of industry and transport, and the discomforts and cost involved in any serious attempt to reduce greenhouse gas emissions, mean that we cannot expect any of the goals of Paris (temperature rise limited to $2^{\circ} \mathrm{C}$ by reducing net emissions to zero by 2060) will be met. The problem is that because carbon dioxide is long-lived in the climate system (hundreds of years, due to recycling between atmosphere, ocean, soil and plants), we will have no way of cooling or restoring a preindustrial climate by reducing $\mathrm{CO} 2$ emissions. The $\mathrm{CO} 2$ just does not go away - an important point often not recognised by the public - so reduced emissions just mean a continued, though slower, warming into the indefinite future.

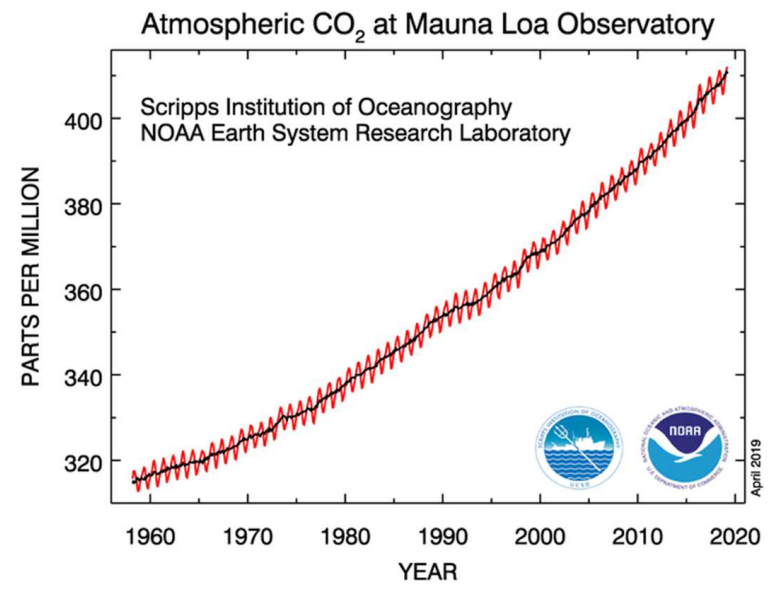

Fig. 4. Week 14-20 April 2019, 413.59 ppm. Curve of atmospheric carbon dioxide concentration, from Mauna Loa observatory in Hawaii, showing rise from 310 ppm in 1958 to $416 \mathrm{ppm}$ in 2019.

What do we do? The young Swede Greta Thunberg has inspired a new generation of young people to environmental action. Enormous energy has been released by this inspiring step. But it is vital that the energy be deployed in the most productive way. So far Ms Thunberg has talked of the need for emissions reduction, and indeed this is important given our complete failure to make any so far when measured on a global scale. But we can see from the above that emissions reduction can only slow global warming, not abolish it. Two strategies have been proposed to go beyond this point:

1. Geoengineering, defined as the use of technical means to increase reflection of energy from the planet and thus cool the climate. It is a short term sticking plaster in the sense that it only works whilst the radiation management technique is being applied, and it does nothing to restrain the growth of $\mathrm{CO} 2$ in the atmosphere, so that some other effects associated with $\mathrm{CO} 2$ continue unabated, notably acidification of the oceans. The most painless technique is marine cloud brightening, whereby drone ships are used in a large array in the ocean. In each ship sea water is pumped up tall masts and out through a fine nozzle so as to inject tiny water particles about one micron across into the bases of marine stratus clouds. As each particle evaporates it leaves a tiny salt crystal which is of a size to make the cloud whiter (known as the Twomey effect), with the overall effect being modelled as significant in cooling the global climate so long as a few hundred ships are used. Models have been done of how different geographical distributions of ships can cause concentrated regional effects, e.g. the expansion of 
Arctic sea ice limits, which would serve to reduce both albedo feedback and the danger of a methane outbreak [7]. The originator of this idea is John Latham, with the innovative technology being designed by Stephen Salter of Edinburgh University. An alternative technique is to release fine powder into the stratosphere, which spreads out in the upper atmosphere and reflects radiation back into space. A disadvantage here is that the process may be construed by the public as air pollution or poisoning, while the impact is crude and impossible to target.

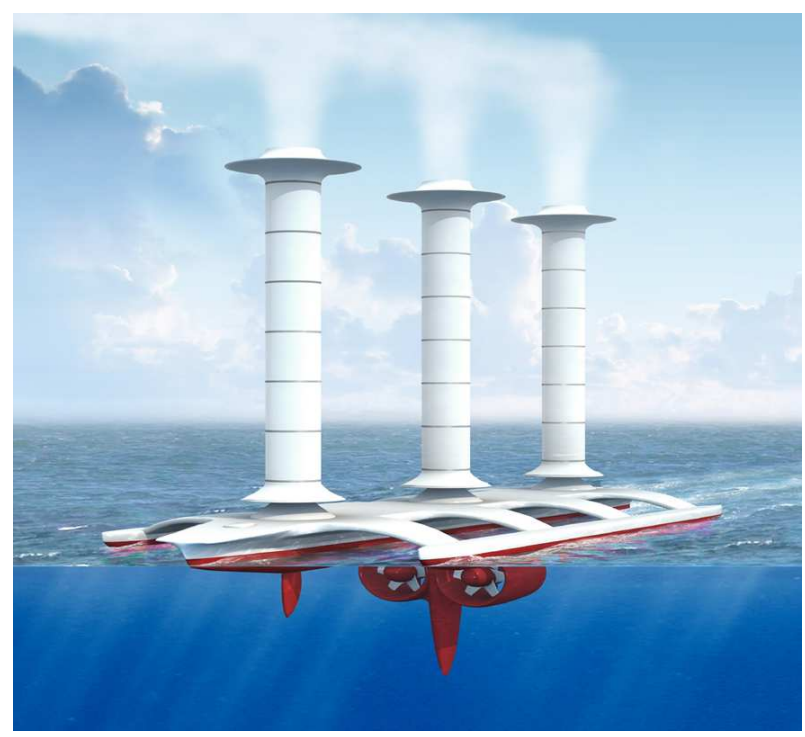

Fig. 5. Design by Stephen Salter (University of Edinburgh) of drone ship to pump sea water up inside Flettner rotors to be injected via a fine nozzle into the bases of marine stratus clouds.

2. Direct Air Capture (DAC). The only real solution to global warming is removing $\mathrm{CO} 2$ from the atmosphere. Going to zero emissions is not enough. We emit some 41 billion tons of carbon into the atmosphere each year. If we can remove at least this quantity we can start to take the atmosphere back to its preindustrial level and restore our former climate. Reduction of emissions just means that we have less to remove each year. CO2 removal is a giant problem in chemistry, physics and technology, but no greater than that of building a huge bomb out of a reaction which was previously only observed among single atoms in a laboratory, as in the Manhattan Project. Slow methods include reforestation (which may well not happen because global forests are being destroyed at an unprecedented rate). Direct air capture is a fast method, designed to keep up with our carbon release with a network of worldwide plants. The problem immediately is to decide what to do with a huge amount of carbon dioxide. One option is to pump it underground into basalt rocks which will react with and thus "fix" the CO2 as a solid (Climeworks, a Swiss company with a plant in Iceland). Another is to create a useful product; present pilot plants plan to create artificial limestone (Blue Planet) which can be used for road building, or using co-production of hydrogen from solar power and electrolysis and then create forms of artificial fuel (Carbon Engineering, Squamish, BC Canada). It is hoped that through technological research the price can be brought down to $\$ 40$ per ton removed, in the same way as solar energy prices have been lowered by $99 \%$ through technological research. The aim is to get $\mathrm{CO} 2$ concentration back to $350 \mathrm{ppm}$ and restore a stable climate which will give us a breathing space to tackle all the other problems of mankind.

These questions are treated in the book "A Farewell to Ice" [8] (Italian translation "Addio ai Ghiacci", Borletti Boringhieri, Torino, 2018). The methane feedback and the direct air capture solution are both treated extensively in a new film "Ice on Fire" (HBO, 2019), directed and narrated by Leonardo DiCaprio, which was released in June 2019.

\section{References}

1. I. V. Polyakov, J. Walsh and R. Kwok, Recent changes of arctic multiyear sea-ice coverage and the likely cause, Bulletin of the American Meteorological Society, 93, 145-152 (2012).

2. F. Marcianesi, G. Aulicino and P. Wadhams, Arctic sea ice and snow cover albedo variability and trends during the last three decades, Geophys. Res. Lett. (2019) in press.

3. J. L. Bamber, M. Oppenheimer, R. E. Kopp, W. P. Aspinall and R. M. Cooke, Ice sheet contributions to future sea-level rise from structured expert judgement, Proc. Nat. Acad. Sci., 116, 11195-11200 (2019).

4. G. Whiteman, C. Hope and P. Wadhams, Vast costs of Arctic change, Nature, 499, 401-403 (2013).

5. J.A. Francis and S. J. Vavrus, Evidence linking Arctic amplification to extreme weather in midlatitudes, Geophysical Research Letters, 39, L06801 (2012).

6. P. Wadhams, G. Budeus, J.P. Wilkinson, T. Loyning and V. Pavlov, The multi-year development of longlived convective chimneys in the Greenland Sea, Geophysical Research Letters, 31, L06306 (2004).

7. J. Latham, A. Gadian, J. Fournier, B. Parkes, P. Wadhams and J. Chen, Marine cloud brightening: regional applications, Phil. Trans. R. Soc. A 372, 20140053 (2014).

8. P. Wadhams, A Farewell to Ice: A Report from the Arctic, Penguin Books Ltd, London (2017). 